\title{
Statistical Analysis of Cymbopogon Chemical Compounds for Oils Species
}

\author{
Khairul Anis Athirah Kamarulzaini, Nurlaila Ismail, Mailina Jamil, Nor Azah Mohd Ali, Sahrim Lias \\ \& Mohd Nasir Taib
}

\begin{abstract}
Cymbopogon essential oil is extracted from the Cymbopogon species which are citronella and lemongrass. This situation may cause confusion and mistake by the selection of the planters. This essential oil is commonly used as aromatherapy and pharmacological activities such as anti-bacterial. The compounds identified in this Cymbopogon oils are mainly geraniol, citronellal, citronellol, geranyl acetate, linalool, limonene and germacrene $D$. The paper aims to summarize the statistical analysis of Cymbopogon chemical compounds between citronella and lemongrass for oils species by using SPSS software. This study consists of data extraction for the oils species using GC-MS machine to identify their chemical compounds. Then, statistical analysis data was performed which consist of the values of abundances. Next, the descriptive statistics data was carried out by evaluating the minimum and maximum data, mean, standard deviation, variance and kurtosis. The result showed that geraniol compound achieved the highest value of abundances and descriptive statistics for both datasets compared to other compounds because it has a role as a fragrance, an allergen and a plant metabolite. This is proven that statistical analysis and descriptive statistics in this study were able to summarize the preliminary data of Cymbopogon oil compounds according to its species which are lemongrass and citronella.
\end{abstract}

Index Terms - Cymbopogon oil, citronella, lemongrass, gas chromatography-mass spectrometry (GC-MS), statistical analysis

\section{INTRODUCTION}

$\mathrm{C}$ ymbopogon essential oils are the oil extracted from the different parts of Cymbopogon grass. Cymbopogon, a genus with belongs to the Poaceae family [1], in a major group of Angiosperms. Cymbopogon's name is derived between "kymbe" (boat) and "pogon" (beard) from the Greek words that refer to the flower spike [2]. The genus of Cymbopogon has 55 species which are generally distributed in the tropical and subtropical regions of Africa, America, Asia and other tropical countries [3, 4]. Natural sources of essential oils can be extracts by several species of Cymbopogon such as C.citratus (lemongrass), C.martini (palmarosa), C.winterianus (citronella java) and C.nardus (jamarosa) [5-7].

This manuscript is submitted on 30th July 2019 and accepted on 10th March 2020. Khairul Anis Athirah Kamarulzaini, Nurlaila Ismail and Mohd Nasir Taib are with the Faculty of Electrical Engineering, Universiti Teknologi MARA, 40450 Shah Alam, Selangor (email: khairulanisathirah@yahoo.com.my)

Mailina Jamil, Nor Azah Mohd Ali and Sahrim Lias are with Department of Herbal Product Development Programme, Natural Product Division, Forest Research Institute Malaysia (FRIM), 52109 Kepong, Selangor.

1985-5389/C 2021 The Authors. Published by UiTM Press. This is an open access article under the CC BY-NC-ND license (http://creativecommons.org/ licenses/by-nc-nd/4.0/).
Two main species of Cymbopogon for this study are lemongrass and citronella. This genus is outstanding for its high content of essential oils that is commercially valuable and used in the cosmetics, perfumery, foods and flavor industries. Additionally, the oils showed several biological activities including anticancer, antimicrobial, pesticides, antiinflammatory, mosquito repellent, and hypoglycemic activity $[4,8]$. The geraniol compounds present the results that has potent anti-inflammatory, anti-angiogenic, anti-cell proliferative, and apoptosis [9].

Table 1 shows the summarized uses of lemongrass oil for various purposes in various countries. For citronella oils, before the recorded history of mankind, these essential oils commonly used in religious ceremonies and embellishment, to therapy and personal use [10]. As active flavor and aromatic ingredients of perfumery and cosmetic mixtures, the demand for these oils is also speedily increasing in hygiene and health care formulations (e.g. oils in toothpastes, mouthwashes etc.) including aromatherapy in fringe medicines [10, 11]. Also, another dimension of their commercial importance to some specific oil components that used as chiral auxiliaries in synthetic organic chemistry and microbial transformations of common structures to allow highly functionalized substances to enlarge economic value [11]. The parts used are the leaves and the whole plant. Lemongrass is non-toxic grass while citronella can be toxic to pollinators [11].

The chemical compounds of these Cymbopogon essential oils have been investigated, which have more than eighty compounds and the most important compounds are geraniol, citronellal and limonene. The other compound that present are citral (a mixture of geranial and neral), citronellol, linalool, elemol, geranyl acetate, 1,8-cineole, $\beta$-caryophyllene, methyl heptenone, and geranyl formate $[5,7,12,13]$. Thus, this study aims to summarize the statistical analysis of Cymbopogon chemical compounds for oils species using SPSS software. This study will also evaluate descriptive statistic of Cymbopogon oils species between lemongrass oils and citronella oils. For the planters and local herbal industries, this project is useful as Cymbopogon species are easily grown and have the potential for future brand development. And also this situation may help planters select the right species of Cymbopogon. 
TABLE 1

C.CITRATUS OIL'S ETHNO-PHARMACOLOGY

\begin{tabular}{|c|c|c|}
\hline Country & Uses & References \\
\hline $\begin{array}{l}\text { Malaysia } \\
\& \\
\text { Indonesia }\end{array}$ & As tea, soup, an emmenagogue & {$[2,14,15]$} \\
\hline Thailand & $\begin{array}{l}\text { As a fragrance, eaten as a } \\
\text { flavoring, medicinal such as a } \\
\text { stomachic and for diabetes }\end{array}$ & {$[2,16-18]$} \\
\hline India & $\begin{array}{l}\text { To repel snakes, drops of } \\
\text { essential oil for gastric troubles, } \\
\text { drops of essential oil adding } \\
\text { with lemon juice for cholera, } \\
\text { used for bathing in cases of } \\
\text { severe fever and headache, as a } \\
\text { sedative for the central nervous } \\
\text { system }\end{array}$ & {$[2,19-21]$} \\
\hline $\begin{array}{l}\text { Middle } \\
\text { East }\end{array}$ & $\begin{array}{l}\text { For pharmacological activities } \\
\text { such as a renal antispasmodic } \\
\text { and diuretic }\end{array}$ & {$[2,22]$} \\
\hline $\begin{array}{l}\text { South } \\
\text { America }\end{array}$ & $\begin{array}{l}\text { As a tea for sore throat, } \\
\text { indigestion and an emetic cause } \\
\text { vomiting }\end{array}$ & {$[2,23]$} \\
\hline $\begin{array}{l}\text { North } \\
\text { America }\end{array}$ & $\begin{array}{l}\text { As a hypotensive for throat and } \\
\text { rheumatism }\end{array}$ & {$[2,24]$} \\
\hline USA & $\begin{array}{l}\text { Used externally healing wounds } \\
\text { and bone fractures }\end{array}$ & {$[2,25]$} \\
\hline Brazil & $\begin{array}{l}\text { Popularly used for } \\
\text { pharmacological such as } \\
\text { diuretic, antispasmodic, } \\
\text { antipyretic, analgesic anti- } \\
\text { inflammatory, and sedative }\end{array}$ & {$[2,26]$} \\
\hline
\end{tabular}

\section{GC-MS FOR CYMBOPOGON OILS}

The lemongrass and citronella fresh samples used in this study were collected from Pahang and Melaka. These samples were dried in room temperature for 3 to 4 days before distilled to obtain the essential oils. After that, the essential oil was stored in the container screw-top clear vial and tightly closed for the safety data information. This study has been carried out by using gas chromatograph and mass spectroscopy (GC-MS). The chemical analysis of the Cymbopogon oils was performed by using the Agilent Technologies 7890A/5975C Series MSD with HP-5MS column $(30 \mathrm{~m} \times 0.25 \mathrm{~mm}$ ID $\times 0.25 \mu \mathrm{m}$ film thickness that showed in fig. 1 . The oven temperature program was the following: initial temperature of $60^{\circ} \mathrm{C}$, increasing by $3{ }^{\circ} \mathrm{C} / \mathrm{min}$ to $180{ }^{\circ} \mathrm{C}$, and held for $10 \mathrm{~min}$. The samples were dissolved in Dichloromethane (DCM) then helium was used as the carrier gas with a $1.0 \mathrm{~mL} / \mathrm{min}$ injector volume. The injector and detector temperature were held at $280{ }^{\circ} \mathrm{C}$. The resulting compounds are presented in terms of by comparing retention times, peak area (\%) and mass spectra. The chemical compounds were identified by matching them to the mass spectral library such as HPCH2205.L; Wiley7Nist05a.L and NIST05a.L. The experiment parameter for GC-MS is tabulated in Table 2. This is a common technique to analyses the chemical compounds [27-30]. GC-MS was used to separate every compound individually [31,32]. This technique has been proven by the previous researcher [30,32], where the chemical composition was discriminated by herbal material while the abundances of the fruits were determined. Other than that, by using this technique, the colour can be analyzed. The best way that previous researcher $[9,33]$ used is focusing on the colour of oil because different colour shows the different chemical compounds. By using GC-MS, it has been found that fresh oil represents the best characters of Cymbopogon oils species.

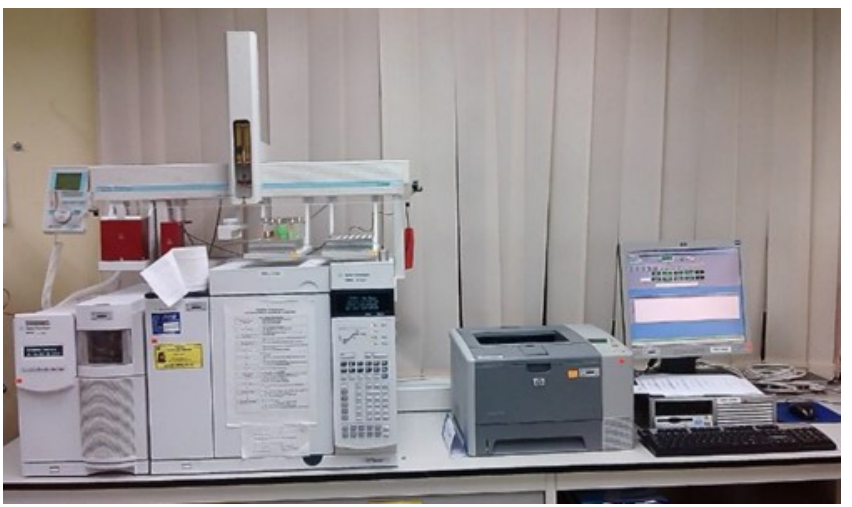

Fig. 1. The Agilent Technologies 7890A/5975C Series MSD

TABLE 2

ANALYSIS CONDITION OF GC-MS

\begin{tabular}{ll}
\hline \multicolumn{2}{c}{ GC-MS Analysis Condition } \\
\hline Column & HP-5MS \\
Length $(\mathrm{m})$ & 30 \\
Diameter $(\mathrm{mm})$ & 0.25 \\
Film thickness $(\mu \mathrm{m})$ & 0.25 \\
Temperature program & $60^{\circ} \mathrm{C}$ for $10 \mathrm{~min}$ then $3^{\circ} \mathrm{C} / \mathrm{min}$ to \\
& $230^{\circ} \mathrm{C}$ for $1 \mathrm{~min}$ \\
Carrier gas & Helium, Flow rate: $1.0 \mathrm{~mL} / \mathrm{min}$ \\
\hline & MS Condition \\
\hline EI & $70 \mathrm{eV}$ \\
Source temperature & $200^{\circ} \mathrm{C}$ \\
Scan range & $20-500 \mu$ \\
Scan speed & $1 / \mathrm{sec}$ \\
$(\mathrm{s} /$ spectrum $)$ & \\
\hline
\end{tabular}

\section{SPSS SOFTWARE FOR CYMBOPOGON OILS}

SPSS software is a complete system which is used for statistical analysis [34]. This SPSS statistics data version 25 is used in this study to analyze all the data of Cymbopogon oils 
in developing descriptive statistics. Fig. 2 showed the step to key in the data in SPSS software for the first time. Firstly, to launch the software, the software need to open. After a few second, the window for data editor will appears and then ready to enter the data. The data that used as input in this research are the abundance of chemical compounds of Cymbopogon oils. The variable view is used to change the variable named if needed. After run the data, the result box will prompt. The result or target of SPSS observation is the species of Cymbopogon either lemongrass or citronella.

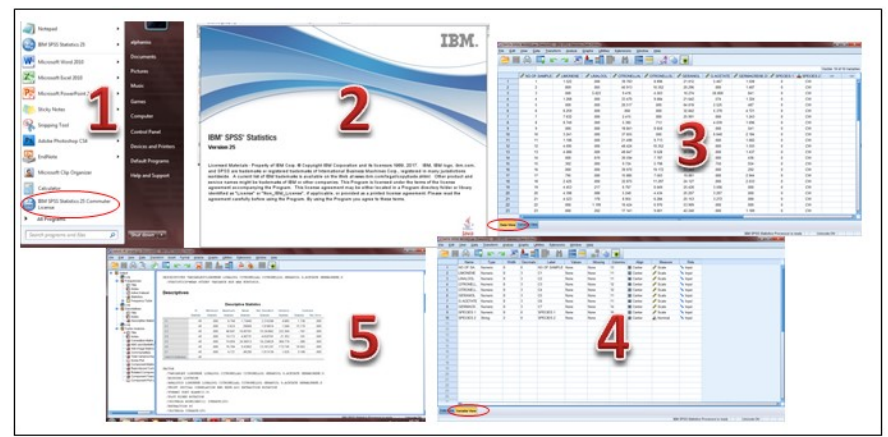

Fig. 2. Guideline in using SPSS software

\section{RESULTS AND DISCUSSION}

\section{A. Cymbopogon Oil Statistical Analysis}

The graph in fig. 3 shows the abundances pattern from GC and GC-MS data analysis of the Cymbopogon oils using seven selected types of chemical compounds such as $\mathrm{C} 1=$ limonene, $\mathrm{C} 2=$ linalool, $\mathrm{C} 3=$ citronellal, $\mathrm{C} 4=$ citronellol, $\mathrm{C} 5=$ geraniol, $\mathrm{C} 6=$ geranyl acetate, $\mathrm{C} 7=$ germacrene $\mathrm{D}$. There are 45 samples of Cymbopogon oils includes lemongrass and citronella. From the general observations for seven types of chemical compounds, it is found that the various peak appeared where it proves that each type of chemical compounds has different pattern of abundances.

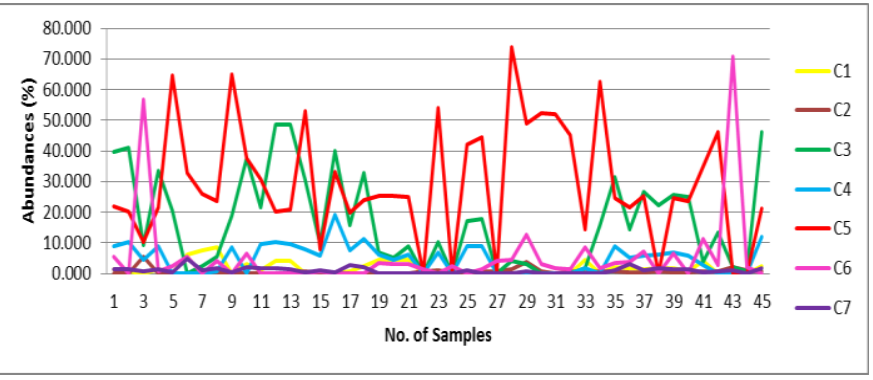

Fig. 3. Abundances of Cymbopogon oils

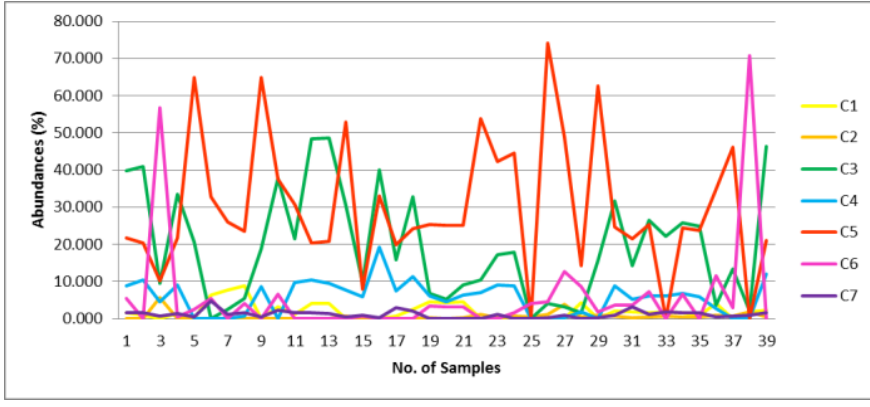

Fig. 4. Abundances of citronella oils

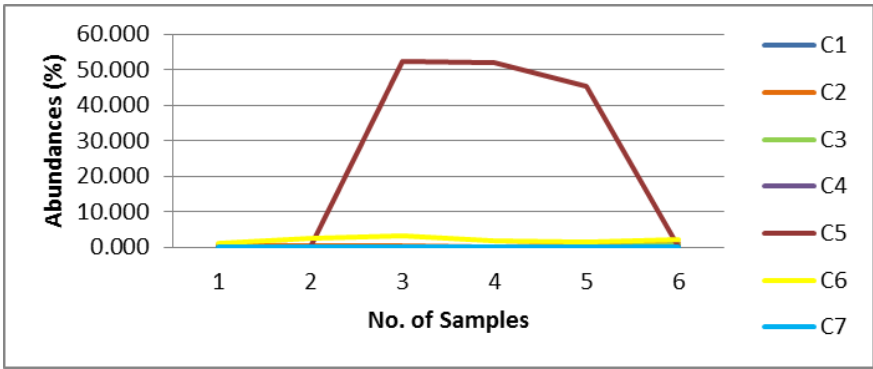

Fig. 5. Abundances of lemongrass oils

Compound 1 which is limonene, has the highest peak is $8.749 \%$ belongs to the number sample eight, follow by the number sample seven which is the abundances are $7.632 \%$. The minimum abundances of this sample are $0.000 \%$ in the range of samples which are from sample twenty-two until sample twenty-seven. For the samples 19, 20 and 21, the value of abundances are in the range $4.398 \%-4.523 \%$. Second is compound 2 which is linalool. The ranges of the peak abundances of linalool compound are between $0.000 \%$ until $5.623 \%$. From the overall data set, it can be seen that the maximum value of abundances is $5.623 \%$ at the sample three. The lowest peak among all the value of abundances belongs to the number of samples from samples 4 until samples 18 which are $0.000 \%$. Third, compound 3 which is citronellal. Number sample twelve and number sample thirteen shows the highest peak compare to other with the value of abundances are $48.424 \%$ and $48.647 \%$, followed by samples 39 which is $46.362 \%$. From overall dataset, the minimum value of abundances which is $0.000 \%$ belongs to the peak of 6 and 25 . In addition, there are three samples with the value of abundances between $0.001 \%$ until $5.000 \%$, which are $2.415 \%$, $4.049 \%, 3.419 \%, 1.629 \%, 3.642 \%$ and $2.133 \%$ for the samples 7, 26, 27, 28, 36 and 38. Next, for compound 4 which is citronellol, it clearly shows the highest peak value of abundances for this compound is $19.172 \%$ belongs to the sample 16. After reviewing the whole dataset, it can be conclude that most of the citronellol compound is in the range $5.000 \%$ to $10.000 \%$ and below $5.000 \%$ belong to the sample $3,5,6,7,8,10,20,25,26,27,28,29,36,37$ and 38 .

Compound 5 which is geraniol. The first peak is $64.818 \%$ belongs to number samples five. The second peak is $64.874 \%$ belongs to the number samples of nine. The third peak is 
$52.926 \%$ which is the sample number fourteen. Lastly, the highest peak among others is $74.054 \%$ which is the sample number twenty-eight. The minimum value of abundances is $0.000 \%$ for the samples 25,33 and 38 . Geranyl acetate shows the pattern of abundances as a compound 6 . It can be seen that the highest peak is $70.784 \%$ belong to the number sample thirty-eight. Sample three clearly show the second highest peak which is the value of abundances is $56.809 \%$, followed by sample number twenty-seven which is 12.7225 . From overall dataset, the most abundances value is ranged between $0.000 \%$ until $5.000 \%$. Lastly, the abundances pattern in compound 7 which is germacrene $\mathrm{D}$. The first peak is $4.721 \%$ belongs to number samples six. The second highest peak is $2.944 \%$ belongs to the number samples of seventeen. The next peak is $3.223 \%$ which is the sample number thirty-one. The next highest peak is $2.944 \%$ belongs to the number samples seventeen. Most the value of abundances is in the range of $0.500 \%$ to $1.000 \%$. It can be concluded that the minimum value of abundances is $0.000 \%$ and the maximum value of abundances is $4.721 \%$ after reviewing the whole dataset.

From all the chemical compounds that found in lemongrass oils that shows in fig.5, compound 5 which is geraniol have the highest value of abundances compares to other which is $52.270 \%$ belongs to number samples three. The second peak is quite high as sample three which is $52.097 \%$ belongs to the number samples of four. The next peak is $45.274 \%$ which is the sample number five. Lastly, it clearly seen that the minimum value of abundances is $0.000 \%$ for the samples 1,2 and 6. Next is compound 6 (geranyl acetate) which is $3.212 \%$ and compound 2 which is linalool that have the value of abundances is $1.082 \%$. The maximum value of abundances for the compound 3 which is citronellal is $0.843 \%$, quite high compare to compound 1 (limonene) which is $0.124 \%$. Lastly, for the lowest maximum value abundances are $0.000 \%$ belongs for both compound 4 (linalool) and compound 7 (germacrene D). In addition, the total number samples of lemongrass oils species are 6 .

\section{B. Descriptive Analysis}

The aim do the preliminary analysis is to inspect and to explore the nature of variables. Table 3 and table 4 shows the summary statistic of the compound of Cymbopogon oils for citronella oils and lemongrass oils that includes the minimum and the maximum number of the data, the means, standard deviation, variance and kurtosis. The function of descriptive statistics is to check the data to describe their characteristics and to check the variable for any violation of the assumptions made by the tests. The kurtosis value provides information about the flatness of the frequency distribution. Positive kurtosis shows the more peaked while negative kurtosis showed less peaked compared to the normal distribution.

TABLE 3

DESCRIPTIVE STATISTICS OF CITRONELLA OILS

\begin{tabular}{|c|c|c|c|c|c|c|c|c|c|}
\hline & \multirow{2}{*}{$\frac{\mathrm{N}}{\text { Statistic }}$} & \multirow{2}{*}{$\frac{\text { Minimum }}{\text { Statistic }}$} & \multirow{2}{*}{$\frac{\text { Maximum }}{\text { Statistic }}$} & \multicolumn{2}{|c|}{ Mean } & \multirow{2}{*}{$\begin{array}{c}\begin{array}{c}\text { Std. } \\
\text { Deviation }\end{array} \\
\text { Statistic }\end{array}$} & \multirow{2}{*}{$\begin{array}{l}\text { Variance } \\
\text { Statistic }\end{array}$} & \multicolumn{2}{|c|}{ Kurtosis } \\
\hline & & & & Statistic & Std. Error & & & Statistic & $\begin{array}{c}\text { Std. } \\
\text { Error }\end{array}$ \\
\hline C2 (LINALOOL) & 39 & 0.0000 & 5.623 & 0.585 & 0.175 & 1.092 & 1.191 & 13.385 & 0.741 \\
\hline C3 (CITRONELLAL) & 39 & 0.0000 & 48.647 & 19.430 & 2.365 & 14.769 & 218.121 & -0.894 & 0.741 \\
\hline C4 (CITRONELLOL) & 39 & 0.0000 & 19.172 & 5.662 & 0.722 & 4.510 & 20.336 & 0.407 & 0.741 \\
\hline C7 (GERMACRENE.D) & 39 & 0.0000 & 4.721 & 5.951 & 0.162 & 1.001 & 1.020 & 3.193 & 0.741 \\
\hline
\end{tabular}

TABLE 4

DESCRIPTIVE STATISTICS OF LEMONGRASS OILS

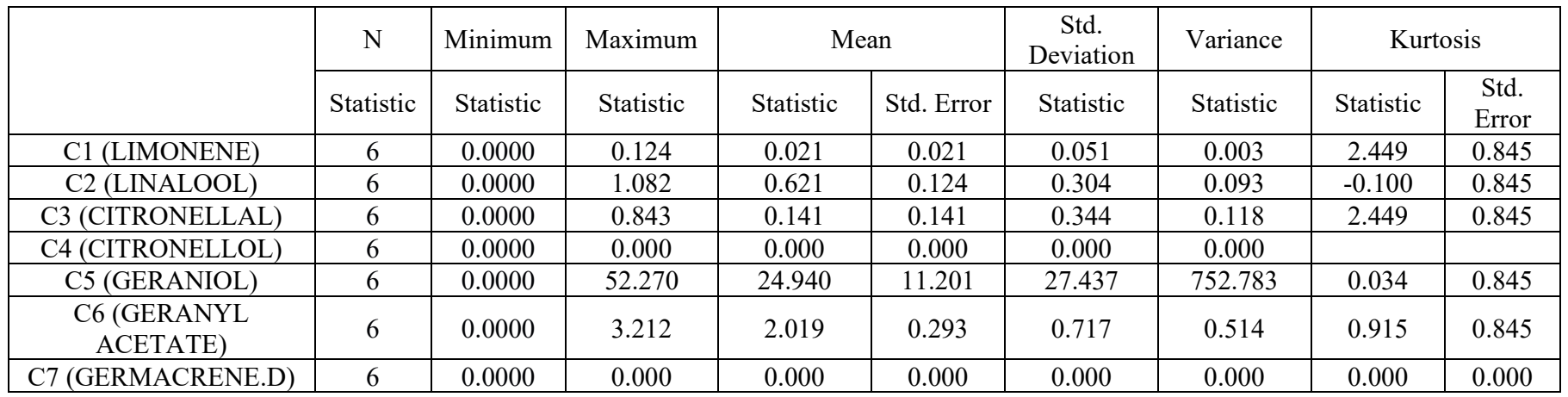


The average is probably the most commonly used method of describing the middle of data. The means of this species is determined by summing all the data for each compound and dividing by the number of samples which are 39 and the formula is expressed in (4.1) [35]. The highest mean are geraniol compounds with 30.040 , followed by citronellal compound which is 19.430. The others mean compound is limonene with 1.998, linalool which is 0.585 , citronellol which is 5.662, geranyl acetate which is 5.951and 5.951for germacrene D compound. The standard error means determines how significantly the samples of the data to be from the true population mean. The lowest standard error mean is germacrene D which is 0.162 and secondly is linalool which is 0.175 . Third is the limonene compound which is 0.362 , followed by citronellol which is 0.722 and geranyl acetate which is 2.259. Lastly for the standard error mean are citronellal compound which is 2.365 and geraniol compound which is 2.890 .

Table 3 also shows the standard deviation statistic which is the number of variability is measure for a set of data from the mean statistic. The formulae for the standard deviation is expressed in (4.2) [35]. It can be seen that the highest standard deviation is the geraniol compound which is 18.043. The second highest is the citronellal compound which is 14.769. Next is geranyl acetate and citronellol which are 14.107 and 4.510. For the limonene compound, the standard deviation statistic is 2.263, followed by linalool which is 1.092 and germacrene D which is 1.001. By using SPSS software, it also shows the result of the variance and the formula is expresses as (4.3) [35]. The result from the standard deviation is the square root of variance statistic. From the table, it can be noticed that geraniol has a larger amount of variance which is 325.555 compared to others like citronellal which is 218.121, geranyl acetate which is 198.995 and citronellol which is 20.336. The variance of limonene compound is 5.121 continue with the linalool compound which is 1.191 and germacrene D compound which is 1.020 .

Last but not least are the values of kurtosis for citronellal chemical compounds. It can be divided into three groups which are normal distribution, positive kurtosis and negative kurtosis. Higher kurtosis means more of the variance in the result. A standard normal distribution has a kurtosis of 3 which is excess kurtosis exactly 0 . A negative kurtosis called platykurtic has a distribution with kurtosis less than 3 which is excess kurtosis $<0$ and a positive kurtosis called leptokurtic has a distribution with kurtosis $>3$ which is excess kurtosis $>0$. There is 4 chemical compounds exist in positive kurtosis such as citronellal compound which is -0.894 , geraniol compound which is 0.135 , citronellol which is 0.407 and limonene which is 1.252. For negative kurtosis, there are linalool which is 13.385, geranyl acetate which is 15.725 and germacrene D which is 3.193 .

Table 4 shows the descriptive statistic for lemongrass oils. The lowest mean for lemongrass oils species are citronellol and germacrene D which are 0.000 . While for the highest means are geraniol compounds with 24.940, followed by geranyl acetate compound which is 2.019 . The others mean compound is limonene with 0.021 , linalool which is 0.621 and citronellal which is 0.141 . The lowest standard error mean are germacrene D and citronellol which are 0.000 and secondly is limonene which is 0.021 . Third is the linalool compound which is 0.124 , followed by citronellal which is 0.141 and geranyl acetate which is 0.293 . Lastly the highest standard error mean are geraniol compound which is 11.201.

Table 4 also shows that the highest standard deviation is the geraniol compound which is 27.437 . The second highest is the geranyl acetate compound which is 0.717. Next is citronellal and linalool which are 0.344 and 0.304 . For the limonene compound, the standard deviation statistic is 0.051 , followed by citronellol and germacrene D which is both are 0.000 . From the table above, it can be clearly seen that geraniol has a larger amount of variance which is 752.783 compared to others like geranyl acetate which is 0.514 , citronellal which is 0.118 and linalool which is 0.093 . The variance of limonene compound is 0.003 continue with the citronellol and germacrene D compound which is 0.000 .

Last but not least are the values of kurtosis for lemongrass chemical compounds. All the compounds for lemongrass oil are exist in positive kurtosis such as limonene and citronellal compound which are 2.449 , geranyl acetate compound with 0.915 , geraniol compound which is 0.034 , and linalool which is -0.100 .

The formula for the mean is expressed as follows:

Mean $=\sum \frac{\sum x_{i}}{n}$

The formula for the standard deviation is expressed as follows:

Standard Deviation $=\sqrt{\frac{(\mathrm{xi}-\mathrm{x})^{2}}{\mathrm{n}-1}}$

The formula for the variance is expressed as follows:

$$
\text { Variance }=\sum \frac{(x-\mu)^{2}}{n-1}
$$

\section{CONCLUSION}

This paper showed that the statistical analysis of data for Cymbopogon chemical compounds oil species and successfully determined the pattern of abundances in seven types of significant compounds by using 45 samples of Cymbopogon oils sample. All these chemical compounds are very significant to classify the species of Cymbopogon oils by setting the values of abundances (\%) as input. This study also includes the minimum and the maximum number of the data, the means, standard deviation, variance and kurtosis. From statistical information, it can be seen that geraniol has the highest values compared to other features. It can be concluded that the significant compound for the Cymbopogon oils species must have geraniol. This technique successfully identified seven significant chemical compounds from many chemical compounds as extracted by GC-MS. The finding showed that the technique proposed is reliable and useful for the Cymbopogon oils classification system. 


\section{ACKNOWLEDGMENT}

This research was supported by the Fundamental Research Grant Scheme (FRGS) Grant (FRGS/1/2018/WAB01/NRE//1).

\section{REFERENCES}

[1] D. Ganjewala and R. Luthra, "Essential oil biosynthesis and regulation in the genus Cymbopogon," Natural product communications, vol. 5, no. 1, p. 1934578X1000500137, 2010.

[2] G. Shah, R. Shri, V. Panchal, N. Sharma, B. Singh, and A. Mann, "Scientific basis for the therapeutic use of Cymbopogon citratus, stapf (Lemon grass)," Journal of advanced pharmaceutical technology \& research, vol. 2, no. 1, p. 3, 2011.

[3] O. Avoseh, O. Oyedeji, P. Rungqu, B. Nkeh-Chungag, and A. Oyedeji, "Cymbopogon species; ethnopharmacology, phytochemistry and the pharmacological importance," Molecules, vol. 20, no. 5, pp. 7438-7453, 2015.

[4] S. Soenarko, "The genus Cymbopogon Sprengel (Gramineae)," Reinwardtia, vol. 9, no. 3, pp. 225-375, 1977.

[5] S. P. Khanuja et al., "Essential oil constituents and RAPD markers to establish species relationship in Cymbopogon Spreng.(Poaceae)," Biochemical Systematics and Ecology, vol. 33, no. 2, pp. 171-186, 2005.

[6] A. Husain, "Essential oil plants and their cultivation," Essential oil plants and their cultivation., 1994.

[7] D. Ganjewala, A. Kumari, and K. Khan, "Ontogenic and developmental changes in essential oil content and compositions in Cymbopogon flexuosus cultivars," Recent Advance in Biotechnology, New Delhi: Excel India Publishers, pp. 82-92, 2008.

[8] A. Akhila, "Chemistry and biogenesis of essential oil from the genus Cymbopogon," in Essential Oil-Bearing Grasses: CRC Press, 2009, pp. $35-116$.

[9] P.-H. Sung, F.-C. Huang, Y.-Y. Do, and P.-L. Huang, "Functional expression of geraniol 10-hydroxylase reveals its dual function in the biosynthesis of terpenoid and phenylpropanoid," Journal of agricultural and food chemistry, vol. 59, no. 9, pp. 4637-4643, 2011.

[10] M. Michalak, "Aromatherapy and methods of applying essential oils," Arch Physiother Glob Res, vol. 22, no. 2, pp. 25-31, 2018.

[11] B. P. Baker, J. A. Grant, and R. Malakar-Kuenen, "Citronella \& Citronella Oil Profile," 2018.

[12] L. Sidibé, J.-C. Chalchat, R.-P. Garry, L. Lacombe, and M. Harama, "Aromatic Plants of Mali (IV): Chemical Composition of Essential Oils of Cymbopogon citratus (DC) Stapf and C. giganteus (Hochst.) Chiov," Journal of Essential Oil Research, vol. 13, no. 2, pp. 110-112, 2001.

[13] C. Silva, F. Moura, M. Mendes, and F. Pessoa, "Extraction of citronella (Cymbopogon nardus) essential oil using supercritical $\mathrm{CO} 2$ : Experimental data and mathematical modeling," Brazilian Journal of Chemical Engineering, vol. 28, no. 2, pp. 343-350, 2011.

[14] I. Burkill, "A Dictionary of the Economic Products of the Malay Peninsula. Vol. 2. Ministry of Agriculture and Cooperatives, Kuala Lumpur, Malaysia," Google Scholar, 1966.

[15] E. Quisumbing, "Medicinal plants of the Philippines," Department of Agriculture and Commerce, Philippine Islands Technical Bulletin., no. $16,1951$.

[16] L. Praditvarn and C. Samhandharaksa, "A study of the volatile oil from stem Lemon grass," J. Pharm. Ass. Siam, vol. 32, pp. 87-92, 1990.

[17] S. Wasuwat, "A list of Thai medicinal plants," ASRCT Research Report, 1967.

[18] B. Mueller-Oerlinghausen, W. Ngamwathana, and P. Kanchanapee, "Investigation into Thai medicinal plants said to cure diabetes," Journal of the Medical Association of Thailand= Chotmaihet thangphaet, vol. 54, no. 2, p. 105, 1971.

[19] R. Rao and N. Jamir, "Ethnobotanical studies in Nagaland. I. Medicinal plants," Economic Botany, vol. 36, no. 2, pp. 176-181, 1982.

[20] D. John, "One hundred useful raw drugs of the Kani tribes of Trivandrum forest division, Kerala, India," International Journal of Crude Drug Research, vol. 22, no. 1, pp. 17-39, 1984.

[21] E. Nair, "Essential oil of East Indian lemongrass: Present position in India and scope of its development," Cultivation \& Utilisation of Medicinal and Aromatic Plants, 1977.
[22] H. Locksley, M. Fayez, A. Radwan, V. Chari, G. Cordell, and H. Wagner, "Constituents of local plants," Planta medica, vol. 45, no. 05, pp. 20-22, 1982.

[23] A. Filipov, "Medicinal plants of the Pilagá of Central Chaco," Journal of Ethnopharmacology, vol. 44, no. 3, pp. 181-193, 1994.

[24] D. Carbajal, A. Casaco, L. Arruzazabala, R. Gonzalez, and Z. Tolon, "Pharmacological study of Cymbopogon citratus leaves," Journal of Ethnopharmacology, vol. 25, no. 1, pp. 103-107, 1989.

[25] M. A. Spring, "Ethnopharmacologic analysis of medicinal plants used by Laotian Hmong refugees in Minnesota," Journal of ethnopharmacology, vol. 26, no. 1, pp. 65-91, 1989.

[26] J. Leite et al., "Pharmacology of lemongrass (Cymbopogon citratus Stapf). III. Assessment of eventual toxic, hypnotic and anxiolytic effects on humans," Journal of Ethnopharmacology, vol. 17, no. 1, pp. 75-83, 1986.

[27] S. F. Ab Rahman, "Analysis of agarwood oil composition via preparative thin layer chromatography," UMP, 2009.

[28] P. E. Keller, "Mimicking biology: applications of cognitive systems to electronic noses," in Proceedings of the 1999 IEEE International Symposium on Intelligent Control Intelligent Systems and Semiotics (Cat. No. 99CH37014), 1999: IEEE, pp. 447-451.

[29] M. Maheshwari, T. Jain, R. Bates, and S. Bhattacharyya, "Terpenoids-xli: Structure and absolute configuration of $\alpha$ agarofuran, - -agarofuran and dihydroagarofuran," Tetrahedron, vol. 19, no. 6, pp. 1079-1090, 1963.

[30] T. Yagura, N. Shibayama, M. Ito, F. Kiuchi, and G. Honda, "Three novel diepoxy tetrahydrochromones from agarwood artificially produced by intentional wounding," Tetrahedron letters, vol. 46, no. 25, pp. 4395-4398, 2005.

[31] P. A. Kumar, "Application of solid phase microextraction in gaharu essential oil analysis," UMP, 2008.

[32] M. S. Najib, M. U. Ahmad, P. Funk, M. N. Taib, and N. A. M. Ali, "Agarwood classification: A case-based reasoning approach based on E-nose," in 2012 IEEE 8th International Colloquium on Signal Processing and its Applications, 2012: IEEE, pp. 120-126.

[33] N. H. Yusoff, M. M. Salleh, M. Yahaya, and M. R. Awang, "The Use of Photoluminescence Spectra of $\mathrm{TiO} 2$ Nanoparticles Coated With Porphyrin Dye Thin Film for Grading Agarwood Oil," in 2006 IEEE International Conference on Semiconductor Electronics, 2006: IEEE, pp. 193-197.

[34] W. J. Dixon and F. J. Massey Jr, "Introduction to statistical analysis," 1951.

[35] A. S. Broto, "Statistics made simple," Mandaluyong City: 2nd ed. National Book Store, 2006.

Khairul Anis Athirah Kamarulzaini graduated with a B.Eng with Honors in Electrical Engineering majoring in System at Universiti Teknologi Mara (UiTM), Malaysia. Currently, she is a Research Assistant and a master student at Faculty of Electrical Engineering (Universiti Teknologi Mara (UiTM), Malaysia). She is taking Msc.Sc in Electrical Engineering and her research concentrate in modelling of Cymbopogon oils species.

Nurlaila Ismail received the B.Sc. in Electrical Engineering with Honors in 2005. She finished the M.Sc. degree in Electrical Engineering in 2011 and got the Ph.D in Electrical Engineering in 2014 at Universiti Teknologi MARA (UiTM), Shah Alam. Currently she teaches at Universiti Teknologi Mara, Malaysia, as a Senior Lecturer.

Mohd Nasir Taib is a senior lecturer at Faculty of Electrical Engineering at Universiti Teknologi MARA (UiTM), Shah Alam, Selangor. He received the B.Sc. in electrical engineering at University of Tasmania, Australia. He finished the M.Sc. degree in Control System with Distinction at University of Sheffiled, United Kingdom and got the Ph.D in Control \& Instrumentation at UMIST, United Kingdom. The 
main research area focuses on advanced signal processing with applications in intelligent control system, biomedical and pharmaceutical systems, process control \& biotechnology, optical fiber sensors and microwave sensors.

Mailina Jamil is a research officer at Herbal Product Development Programme, Natural Product Division, Forest Research Institute Malaysia (FRIM), 52109 Kepong, Selangor.

Nor Azah Mohd Ali is a senior research officer at Herbal Product Development Programme, Natural Product Division, Forest Research Institute Malaysia (FRIM), 52109 Kepong, Selangor. She received her degree in bachelor of science at universiti of waterloo, canada in 1985. She finished her master of science at universiti kebangsaan malaysia in 1996 and got philosophy of science at universiti putra malaysia in 2004. Her specialized are chemistry (natural product chemistry) essential oil analysis and processing cosmetic formulation and product Development.

Sahrim Lias is a research officer at Herbal Product Development Programme, Natural Product Division, Forest Research Institute Malaysia (FRIM), 52109 Kepong, Selangor. 